\title{
O NARRADOR FINGIDOR EM O MAL DE MONTANO, DE ENRIQUE VILA-MATAS
}

Rosana Arruda de SOUZA

\section{RESUMO}

Em tempos de avulto sobre a querela do autor, ou seja, sobre as teorias literárias que promulgam ora a morte do autor, ora o seu retorno, propomos, neste trabalho, um contracaminho. Tendo por objeto o romance O mal de Montano, objetivamos colocar, no centro do palco, o narrador, ao invés do autor, e articular a possibilidade do primeiro ser um fingidor, de quando mobiliza as peças do jogo e se esconde atrás de várias máscaras. Para tanto, dialogaremos com a teoria iseriana, a respeito da recepção e dos atos de fingir, e com autores que possam contribuir com a discussão aqui proposta.

PALAVRAS-CHAVE: Autor; Narrador; Máscaras.

\section{THE SIMULATOR NARRATOR IN THE EVIL OF MONTANO, BY ENRIQUE VILA-MATAS}

\section{ABSTRACT}

In times of great quarrel over the author, that is, about the literary theories that promulgate sometimes the author's death, sometimes the his return, we propose, in this work, a counterpath. Having as its object the novel The Evil of Montano, we aim to place, in the center of the stage, the narrator, instead of the author, and articulate the possibility of the first being a simulator, when he mobilizes the pieces of the game and itself to hides behind various masks. To this end, we will dialogue with the iserian theory, regarding the reception and to acts of pretending, and with authors who can contribute to the discussion proposed here.

KEYWORDS: Author; Narrator; Masks.

\section{EL NARRADOR SIMULADOR EN EL MAL DE MONTANO, POR ENRIQUE VILA-MATAS}

\section{RESUMEN}

En tiempos de gran discusión sobre el autor, es decir, sobre las teorías literarias que promulgan a veces la muerte del autor, a veces su regreso, proponemos, en este trabajo, un camino contrario. Teniendo como objeto la novela El mal de Montano, nuestra propuesta es colocar, en el centro del escenario, al narrador, en lugar del autor, y articular la posibilidad de lo primero ser un simulador cuando moviliza las piezas del juego y se esconde detrás de varias máscaras. Con este fin, vamos a dialogar con la teoría iseriana, con respecto a la recepción y los actos de simulación, y con los autores que pueden contribuir a la discusión propuesta aquí.

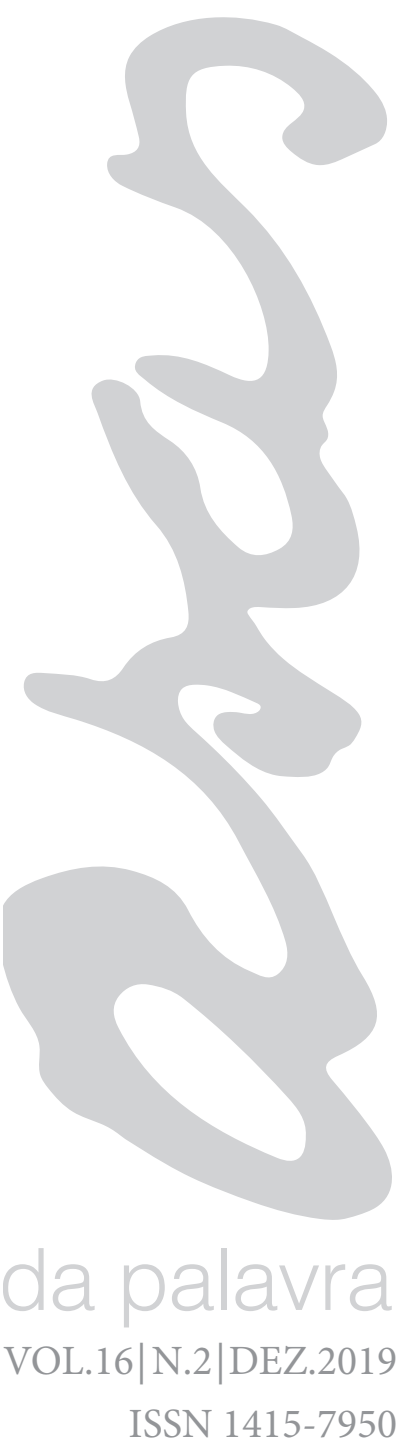

PALABRAS CLAVE: autor; Narrador; Máscaras. 


\title{
INTRODUÇÃO
}

O romance $O$ mal de Montano foi publicado em 2002, sob a autoria do escritor espanhol Enrique Vila-Matas. Este autor é conhecido por mesclar, de forma bastante ardilosa, realidade e ficção em seus textos. Trazendo com frequência um narrador-protagonista que também cumpre o papel de escritor, Enrique Vila-Matas constrói verdadeiras teses literárias travestidas de romance.

Estamos diante de algo a se cristalizar na Literatura contemporânea: escritores que também são estudiosos da Literatura, conhecem muito bem as discussões em voga e as trazem para o romance, como o faz Enrique Vila-Matas, quando cria narradores embebidos na teoria de Blanchot (2005), sobre o desaparecimento do autor, caso do romance em análise. Segundo essa teoria, o autor desapareceria porque, mesmo em uma narrativa autobiográfica, existe o processo de passagem entre outros eus - o narrador e o personagem. $\mathrm{O}$ autor não seria mais $\mathrm{o}$ sujeito da realidade factual, não é mais o escritor,

\begin{abstract}
mas sua metamorfose na sombra que é o narrador tornado 'personagem' do livro, o qual, na narrativa, escreve uma narrativa que é a própria obra e produz, por sua vez, as outras metamorfoses dele mesmo que são os diversos "eus" cujas experiências ele conta (BLANCHOT, 2005, p. 21).
\end{abstract}

O mal de Montano traz a história do narrador-protagonista Rosário Girondo, acometido por uma doença imaginária, a qual ele nomeia homonimamente ao nome do romance aqui analisado. A doença acomete as pessoas e a Literatura, esta corre o risco de desaparecer insuflada por gente que, como diz Rosário, acha-se capaz de escrever um livro. Enquanto isso, as pessoas sofrem com os sintomas: uns se tornam ágrafos, caso do filho de Rosário, Montano (daí o nome da doença); outros passam a ver tudo sob um ângulo literário, caso do próprio Rosário, quando passa a relacionar pessoas e situações a personagens e a trechos de romances. Como uma solução para o mal, Rosário quer a todo custo desaparecer, tonar-se ele mesmo parte da Literatura para quem sabe assim consiga uma cura e evite a morte dela.

Em determinado momento, Rosário dá o que chamamos de salto iseriano, pois observamos a prática do processo de criação literária descrito por Wolfgang Iser (1999). O narrador de $O$ mal de Montano confessa sua farsa: Montano não existia, era invenção sua. "O como 
aquilo que designa - indica que o mundo representado no texto deve ser visto apenas como se fosse um, embora não seja" (ISER 1999, p. 69, grifo do autor). Assim, deixa-se às claras o como se fosse real quando Rosário Girondo faz questão da tomada de ciência, por parte do leitor, da história encenada e dos elementos inventados.

Sendo invenção justamente o mote da história, (pois foi inspirado no filho o nome da doença), o leitor começa a imaginar quantos mais personagens seriam pura invenção de Rosário. Por fim, temos um narrador também como uma farsa (ou um fingidor contumaz), pois ele confessa que Rosário não é seu verdadeiro nome e chegamos ao final da história, sem descobrir a verdade.

Temos um narrador a todo o momento potencializado pelo jogo entre verdade e não verdade e pela interposição de máscaras: além da mentira de seu nome, cada personagem da história carrega algo de seu, dando abertura à ideia de alter egos. Nessa esteira, Rosário não era seu nome, mas era o nome de sua mãe a qual, aliás, também era escritora; seu filho inventado tinha uma mãe com alguns detalhes semelhantes à mãe de Rosário; sua amiga imaginária, Margot Valerí, era a mesma amiga imaginária de sua mãe; sua esposa se chama Rosa (supressão do nome Rosário); sua data e cidade de nascimento coincidem com as do escritor da realidade factual Enrique Vila-Matas.

Enfim, estamos diante de uma verdadeira salada de signos de ficção e signos de realidade (LEE, 2011), cuja articulação entre ambos vai muito além de se propor a fácil solução de um "pacto fantasmático" (LEJEUNE, 2008, p.43), uma vez que estaria no narrador a potência a conduzir os tantos sentidos da história, ao invés de pensarmos num autor reinante em função da data e da cidade de nascimento de Enrique Vila-Matas aparecerem na narrativa. Propomos, pois, mediar a discussão presente neste artigo considerando a constante remodulação de pactos impetrada pelo narrador e pelo leitor - por meio dos pressupostos teóricos dos grandes jogadores da história, a compactuarem os "atos de fingir", nas palavras de Iser (1999).

\section{COMO SE FINGE NA HISTÓRIA}

Hans Robert Jauss (1979) e Wolfgang Iser (1999) anunciaram nos estudos de Literatura o diálogo entre os elementos autor-textoleitor, dando relevância à recepção, ou seja, ao leitor e às diversas leituras com o poder de nortearem a construção de sentidos de um 
texto, quando antes os holofotes se voltavam para o autor. No autor se concentravam todas as possibilidades de construção das narrativas, seja as do primeiro processo, o de criação através da escrita; seja as do processo pós-escrita, e o leitor lia a obra buscando o rastro do elemento criador, dados biográficos de uma vida e sobrevida a chancelarem um sentido único para o produto da escrita.

Conforme Terry Eagleton (1997), podemos dividir a história moderna da Literatura em três partes: uma centrada no autor, uma centrada no texto e, a última, em voga, centrada no leitor. As teorias antecedentes à centralização no leitor não devem ser ignoradas, pois a partir delas e das lacunas por elas deixadas, criaram-se as teorias posteriores. Para Iser (1999), a intenção do autor e a mensagem da obra aparecem como plano de fundo para as discussões que as substituíram pelo impacto do texto literário sobre o receptor e o que acontece a ambos no ato de leitura.

Podemos dizer que as teorias continuam se reformulando, sempre colocando em trânsito, ora de ida, ora de volta, os espectros do autor, do texto e do leitor. Depois do postulado de Eagleton, houve novas mudanças, até chegarmos aos estudos pós-estruturalistas em que a escrita (ou a escritura, numa visão derridiana) ganha todo o vulto, tornando-se quase uma potência independente: morre o autor (BARTHES, 1967), e o leitor, se tem alguma importância, continua cada vez mais enredado na teia iseriana, agora, no entanto, sem a potência de ver e ver-se naquilo que Iser (1999) chamou de atos de fingir.

$\mathrm{E}$ as coisas não pararam por aí. Juntamente ao boom midiático através do qual observamos a multiplicação de imagens de um mesmo eu, vem entrar em cena, novamente, o autor, agora, sob novas facetas. Estamos falando de um elemento lacunar entre a máscara e o rosto, um espectro, perseguido incessantemente pelo leitor a fim de conjugar, a revelia de um sentido para a história, algo ainda potente o suficiente para se pôr como responsável pela história. Em outras palavras, equiparamos este espectro à negatividade proposta por Iser (1999), sendo ela algo comum da própria Literatura:

\footnotetext{
a obra literária não deve ser considerada um registro documental de algo que existe ou já existiu, mas antes uma reformulação de uma realidade identificável, reformulação que introduz algo que não existia antes. $[\ldots]$. 
Todavia, como os elementos estranhos não podem manifestar-se sob as condições vigentes no caso da manifestação de concepções familiares ou já existentes, o que a literatura traz para o mundo só pode revelar-se como negatividade (ISER, 1999, p. 21, 32-33)

Como dando uma resposta ao acirramento pós-estruturalista em torno de um autor morto, ou do elemento criador (Deus) morto, Foucault adiantou:

não chega, evidentemente, repetir a afirmação oca de que o autor desapareceu. Do mesmo modo, não basta repetir indefinidamente que Deus e o homem morreram de uma morte conjunta. Trata-se, sim, de localizar o espaço deixado vazio pelo desaparecimento do autor, seguir de perto a repartição das lacunas e das fissuras e perscrutar os espaços, as funções livres que esse desaparecimento deixa a descoberto (FOUCAULT, 1992, p. 41)

Em uma esteira semelhante, Diana Irene Klinger (2006) afiançou a possibilidade de um retorno do autor.

Sustentar a existência de um retorno do autor implica necessariamente entrar no debate sobre a produção da subjetividade em relação com a escrita. De fato, esses dois termos estão em estreita relação: da Antiguidade até hoje, a escrita performa a noção de sujeito (KLINGER, 2006, p. 24)

Isso nos inspira a pensar no como são produzidas as diversas relações entre o leitor e a escrita, e a partir delas seriam produzidas as também diversas relações de subjetividade. E do processo de leitura partirá também o eu a ser construído dos dois lados do plano criativo: seria o eu-autor, o eu-diluído e submetido à escrita, ou um eu versátil nascido junto ao jogo midiático, tendendo a permanecer como espectro? Nesta instância final, pretendemos centralizar, pois, o narrador, mas não mais aquele imbuído nas teorias literárias de praxe, sugerimos um narrador, o qual pouco desejamos classificar, por exemplo, sob um postulado genettiano ${ }^{1}$. Sugerimos um narrador mais próximo a nós, impassível a classificações, com o qual queremos dialogar e indagar suas artimanhas, apenas isso.

No caso de nosso objeto de análise, a história se inicia com o filho de Rosário Girondo, Montano, sendo acometido pela doença que depois ganhou um nome homônimo ao dele:
1 Basicamente, Genette (1979) traz três classificações para o narrador de acordo com a proximidade ou distanciamento deste em relação à história contada. Assim, temos um narrador heterodiegético, ausente da história, contando-a, mas sem participar dela. Temos também o narrador homodiegético, que conta a história e participa dela como personagem secundário. Por fim, temos o narrador autodiegético, num papel de protagonista da história, contando sua experiência de vida. No caso de $O$ mal de Montano, ao invés de querer enquadrar o narrador, interessa-nos analisá-lo tomando por base o seu distanciamento ou aproximação em relação ao proprio leitor, uma vez que aquele faz questão de entregar a este os elementos utilizados no fingimento. 
Em fins do século 20, o jovem Montano, que acabara de publicar seu perigoso romance sobre o enigmático caso dos escritores que renunciam a escrever, foi apanhado nas redes de sua própria ficção, apesar de sua tendência compulsiva à escrita, e converteu-se num escritor totalmente bloqueado, ágrafo trágico. (VILA-MATAS, 2005, p. 13)

Vemos erguida, nesse trecho, a potência da escrita e nela se embebeu o próprio personagem-escritor Montano, após praticar o gesto de criação literária, tornou-se, paradoxalmente, ágrafo e, sim, trágico, visto que o criador se feriu com as farpas de sua própria criatura. Porém, em trechos seguintes, será ao narrador atribuído o poder na história.

À revelia de estar também doente com o mal de Montano, Rosário Girondo trapaceia o leitor e trapaceia a própria escrita e o "mal" causado por ela. A incipiência disso tudo ocorre quando descobrimos que o parágrafo inicial do romance se trata, na verdade, de parte do diário escrito pelo narrador:

\footnotetext{
Vou me deitar, sinto-me cansado depois da viagem e também fatigado de tanto escrever neste diário que mantenho há anos e que hoje, já desde a primeira linha - quando escrevi isso de "Em fins do século 20, o jovem Montano ..." -, notei que podia se converter, movido por um impulso misterioso, no ponto de partida de uma história que exigiria leitores, sem poder ficar oculta entre as páginas deste diário íntimo. (VILA-MATAS, 2005, p. 19)
}

Ora, a doença do filho do narrador se trata de fato já passado, tanto que fora até assentado em um diário. A doença do filho se trata de uma narrativa muito bem articulada pelo narrador e não é o diário, por ser imbuído em um gênero em que se registram fatos reais da vida, que deixará de atestar o teor de narrativa (ou seja, de algo já filtrado com vários toques de invenção): o narrador desempenha a função de escritor de diário, mas finge. Tudo quanto fora contado até então era uma farsa, pois o diário se transformará em um romance, no qual ele incluirá as biografias de seus diaristas favoritos: comecei a converter em romance meu diário [...] fui depois construindo uma biografia impostada por meio da injeção de fragmentos das vidas ou das obras de meus diaristas favoritos (VILA-MATAS, 2005).

A afirmação de que o diário virou um romance, acontece quando Rosa, a esposa de Rosário, surpreende a escrita do marido, questiona 
- O que é o mal de Montano?

- Um romance.

- Onde fica isso - perguntou.

- O quê?

- O mal de Montano.

Fui até a mesinha de cabeceira e tirei o diário, este diário. E mostrei-o a ela.

Leu umas quantas páginas do diário e, horrorizada, perguntou-me se eu tinha me incorporado a esse pelotão de torpes que acreditam estar a literatura acabando e que responsabilizam o mercado, se era um desses peixes mortos que acreditam que a literatura está em crise [...] Trepamos como se o mundo e a literatura estivessem acabando [...] Quando tudo acabou, saí para o terraço e vi a espuma das ondas batendo contra a proa de um barco que navegava à distância. $\mathrm{O}$ sol do meio-dia brilhava, a superfície da água já não era um espelho. E não sei. Diria que comecei a perder de vista o mal de Montano (VILA-MATAS, 2005, p. 100, 101).

A história vai apresentando declarações surpreendentes, pelas quais poderíamos retomar os atos de fingir descritor por Iser (1999), com a diferença de que, agora, nós leitores não estamos presos na teia e olhando-nos a nós mesmos de lá, ao contrário disso, o narrador parece nos convidar a descer e ver como ele provoca a suspensão de determinados signos para dar lugar à combinação deles com outros, construindo novos sentidos, e sobrepondo histórias e máscaras de si.

Segundo Iser (1999), os atos de fingir se dividem em: seleção, combinação e autodesnudamento. A seleção consiste na apreensão de realidades referenciais; depois de suspensas, elas são colocadas entre parênteses e invalidadas, passando a ter importância o modo como são compreendidas no texto. A combinação acontece quando as realidades referenciais postas em suspensão são combinadas com elementos imaginários ou não, sendo importante a transgressão daquele mundo suspenso. "Ao serem transgredidas posições estabelecidas no texto, dado e alteridade se convertem em possibilidades um para o outro. [...]. O significado literal, representacional permanece latente como uma orientação para o que deve ser concebido dali em diante" (ISER, 1999, p. 72). Já o autodesnudamento "assinala que o mundo do texto não é de fato um mundo, mas para fins específicos deve se considerado como tal" (ISER, 1999, p. 72).

No caso de $O$ mal de Montano, observamos o narrador jogar na cara do leitor o processo de criação literária, assim, os movimentos de seleção, combinação e autodesnudamento, tornam-se algo de 
alteridade entre narrador e leitor, ao invés de algo íntimo de tal processo:

[...] neste último mês perdi bastante de vista o mal de Montano, diminuí a intensidade de minha obsessiva tendência ao literário. Diria que deixei de me comportar como Borges, que agia como se as pessoas não se interessassem por outra coisa além da literatura. Não perdi de vista, porém, $\mathrm{O}$ mal de Montano, a nouvelle que terminei de escrever em Faial, depois de uma transa selvagem, a nouvelle em que se entrelaçam a ficção e a minha vida real. Há muito de autobiográfico em $\mathrm{O}$ mal de Montano, mas também muita invenção. Não é verdade, por exemplo - quase não é necessário dizêlo -, que Rosa seja diretora de cinema, Rosa -, como muitos de meus leitores já sabem - é agente literária e, sobretudo, é minha eterna namorada, vivemos juntos a quinze anos, não nos casamos nem no civil, não tivemos filhos, tampouco os tivemos com terceiros. De modo que Montano não existe (VILA-MATAS, 2005, p. 106)

Os movimentos de seleção e combinação são exumados das afirmações do narrador de que na sua escrita "se entrelaçam ficção e realidade"(VILA-MATAS, 2005,p. 106, que "há muito de autobiográfico em O mal de Montano, mas também muita invenção" (VILA-MATAS, 2005, p. 106), e que, por fim, Montano era pura invenção. No trecho abaixo, vislumbramos o como fictício e imaginário tiveram de se entrelaçar para dar conta da passagem do diário ao romance. Assim, o narrador continua a entregar as peças utilizadas e articuladas para contar sua história no diário, ao final, uma narrativa em que ele cria a si próprio por meio da linguagem, tornando-se outro:

não é a revelação de uma verdade o que meu diário anda buscando, mas sim informação sobre minhas constantes mutações. Meu diário existe há anos, mas só há alguns meses começou a se converter num romance, só depois que, em novembro do ano passado, viajei a Nantes e imaginei que visitava um filho inventado. Comecei a converter em romance meu diário, sendo o narrador que sou, mas fazendo-me passar por um crítico literário, fui depois construindo uma biografia impostada por meio da injeção de fragmentos das vidas ou das obras de meus diaristas favoritos [...] (VILA-MATAS, 2005, p. 245)

O fictício e o imaginário estão presentes na experiência cotidiana, na mentira, no sonho, na ilusão ou em nossos momentos de devaneios (ISER, 1999). Entretanto, o fictício não pode ser tomado por mentira; quando mentimos, temos um propósito distinto ao da Literatura, 
ao invés de enganar, cria o como se, de modo que seu receptor sabe da inexistência do que está sendo contado, portanto, não está sendo enganado. Quando Rosário confessa a inexistência do filho, o que ele fez se equipara a uma metalinguagem, em que ele conta ao leitor um dos signos de ficção utilizado para escrever seu romance.

"A mentira excede, ultrapassa a verdade, e a obra literária ultrapassa o mundo real que incorpora" (ISER, 1999, p. 68). O autor pontua a impossibilidade de se encontrar uma definição para fictício e imaginário, sendo possível apreendê-los apenas pela observação de suas manifestações. O fictício compele a forma do imaginário, mas depende dele para construir plenamente aquilo que se tem em mira (ISER, 1999).

O narrador fala de suas constantes mutações, mas ainda assim, permanece seu status último de narrador: "sendo o narrador que sou" (VILA-MATAS, 2005, p. 245). Independente de quantas mutações ele sofra, será sempre um narrador, ainda que esteja desvinculado da instância ontológica precípua para ser alguém: o nome, como o faz no trecho seguinte, fazendo-nos entender sua condição de inominável:

\begin{abstract}
GIRONDO, Rosário (Barcelona, 1948). Que outros se escondam em pseudônimos ou inventem heterônimos. O meu sempre foi o matrônimo. Existe essa palavra, existe a palavra matrônimo? Eu diria que existe tudo que se nomeia. Rosário Girondo é como eu assino meus livros sempre, Rosário Girondo é o nome da minha mãe. Muitas vezes tive que ouvir que era meu pseudônimo. Não, é meu matrônimo. Quantas vezes precisarei dizê-lo Como o nome da mãe pode ser um pseudônimo (VILA-MATAS, 2005, p. 126)
\end{abstract}

Num único trecho, o narrador articula duas informações à altura de autodesnudamentos. A primeira se refere a não verdade de seu nome, pois Rosário Girondo era apenas o nome de sua mãe. A segunda chancela signos de realidade basilares para pensarmos numa sombra autoral no texto: "Barcelona, 1948" (VILA-MATAS, 2005, p. 126), a cidade e o ano de nascimento, coincidentes com os do autor da realidade factual Enrique Vila-Matas. No entanto, quem ainda joga são narrador e leitor; de posse dessa informação, o leitor pode escolher fazer dela ou o elemento que será suspenso, dando a ele certa importância, pois suspender deixa de coincidir com anular, ou mais um dos tantos elementos de combinação.

Ao invés dos signos referidos, optamos por suspender o nome 
Rosário Girondo, afinal esse nome constitui uma falsidade. Porém, permanecemos com o narrador, continuando a imperar e a mobilizar a história, a despeito de qualquer ambiguidade a mais que possa atrelarse a ele. Por que persistimos em atrelar tal importância ao narrador? Porque ele tem existência própria, independente de um nome e de uma data e um local de nascimento. Como um espectro, ele tem sua destruição impedida, pois transita livremente entre as instâncias do ser e do não ser, em melhores palavras, fictício e imaginário. Já o autor dependeria daqueles signos de realidade para se manter "vivo" na história; dependeria também do fio de teia com que insistimos a ligá-lo ao plano do escritor da realidade factual.

No trecho abaixo, o narrador despeja mais um autodesnudamento proposital sobre o leitor: sua amiga imaginária Margot Valeri fora, na verdade, inventada por sua mãe.

Em muitos momentos de seu diário [da mãe de Rosário]
surpreende a violência verbal, surpreende em alguém
como ela, que nunca levantava a voz, e era, como muitas
pessoas deprimidas, uma pessoa pacífica, muito calma.
Mas no diário era terrível, destrutiva quando falava das
pessoas. Detestava quase todo o mundo, menos Margot
Valerí, suposta amiga sua, velha aviadora chilena, uma
mulher inventada, talvez seu ater ego, uma mulher
inexistente (VILA-MATAS, 2005, p. 129)

Então, além de estarmos diante de um narrador sem nome próprio e sem data e local de nascimentos próprios, estamos diante de um narrador, que até a amiga imaginária era "emprestada" de outrem. Porém, ao contrário disso tudo alimentar um enfraquecimento da imagem do narrador, só eleva sua potência, por ser alguém com poder de transitar entre vários campos ontológicos.

Ao final da história, continuamos sem saber quem é o narrador, sua existência se abre a várias conjecturas. Ora, o narrador poderia não ser ele próprio, mas poderia ser a mãe, afinal carrega o nome dela. Poderia ser o próprio Montano, já que diante de um narrador tão ardiloso, deixamos de contar com o impossível, pois tudo passa a ser possível.

\section{CONSIDERAÇÕES FINAIS}

Neste trabalho, propusemos analisar o romance $O$ mal de Montano dando relevância à figura do narrador, ao invés do autor, por considerarmos que é o primeiro quem mobiliza as peças do jogo, sendo 
Para a análise, propusemos um diálogo com Iser, bem como com autores que viessem a contribuir com a discussão proposta.

Assim, ao longo do trabalho, acabamos por utilizar, também, teorias mais atuais a respeito da figura autoral e pudemos perceber que a perspectiva em que se defende um desaparecimento do autor, ou a sua morte, deixa uma lacuna. Parece que o leitor necessita se apegar a algo na história que entre como cúmplice responsável naquilo que Iser (1999) chama de fingimento. Em melhores palavras, não dá para o leitor fingir sozinho, ele precisa de parceria.

O fingimento em questão é a própria Literatura e tal fingimento nos leva como leitores a certos atos e parecemos apreciar tal atividade, apesar de saber que se trata de uma ilusão (ISER, 1999). Embora esclareça ao leitor os elementos selecionados para criar sua história, o narrador de $O$ mal de Montano perfaz desde sempre um fingidor, porque não se desfaz da máscara de seu nome - Rosário Girondo.

O narrador promove um autodesnudamento proposital na história, mas nós leitores, apesar dos elementos que apontam a farsa ontológica de Rosário Girondo (ou seja, ele não é quem diz ser), caminhamos com isso até o final da história, sem querermos angariar uma verdade ou uma afirmação de que narrador e autor são a mesma pessoa.

Ainda segundo Iser, "se gostamos de viver uma experiência nesse reino ilusório, isso talvez revele algo sobre nós" (1999, p. 66). Com já dissemos, a literatura ultrapassa o mundo real (ISER, 1999). Assim, talvez a decisão do leitor, de quando entre a máscara e o ser, opte pela máscara, evidencie que seu desejo é o de continuar no mundo ilusório, onde o narrador não é ele mesmo, e até o leitor se dá a chance de deixar de ser a si.

\section{REFERÊNCIAS:}

BARTHES, Roland. A morte do autor, São Paulo, 1967. Disponível em: <<https:// filosoficabiblioteca.files.wordpress.com/2013/10/barthes-a-morte-do-autor-2. pdf $>>$. Acesso em: 14 de maio de 2019.

BLANCHOT, Maurice. O livro por vir. Tradução de Leyla Perrone-Moisés. São Paulo: Martins Fontes, 2005.

EAGLETON, Terry. Fenomenologia, hermenêutica, teoria da recepção. In: Fontes, 1997. . Teoria da literatura: uma introdução. $3^{\mathrm{a}}$ ed. São Paulo: Martins

FOUCAULT, Michel. O que é um autor. $3^{\mathrm{a}}$ ed. Lisboa: Passagens, 1992. 
GENETTE, Gérard . Discurso da narrativa. Lisboa: Arcádia, 1979.

ISER, Wolfgang. O fictício e o imaginário. In: ROCHA, João Cezar de Castro (org.). Teoria da ficção: indagações à obra de Wolfgang Iser. Tradução: Bluma Waddington Vilar, João Cezar de Castro Rocha. Rio de Janeiro: EduERJ, 1999.

JAUSS, Hans Robert. O prazer estético e as Experiências Fundamentais da Poiesis, Aesthesis e Katharsis. In: LIMA, Luis (org.). A literatura e o leitor - textos de Estética da Recepção. Rio de Janeiro: Paz e Terra, 1979.

KLINGER, Irene Diana. Escritas de si, escritas do outro. 209 f. Tese de doutorado, Instituto de Letras da Universidade Estadual do Rio de Janeiro, 2006.

LEE, Henrique de Oliveira. Imaginário e drama da individuação em Yukio Mishima. 226 f. Tese de doutorado, Programa de Pós-Graduação em Estudos Literários da Universidade Federal de Minas Gerais, 2011.

LEJEUNE, Philippe. O pacto autobiográfico: de Rousseau à internet. Belo Horizonte: Editora UFMG, 2008.

VILA-MATAS, Enrique. O mal de Montano. Tradução de Celso Mauro Paciornik. São Paulo: Cosac Naify, 2005.

Mestre em estudos de linguagem, com concentração na área de estudos literários, pelo Programa de Pós-Graduação em estudos de linguagem da Universidade Federal de Mato Grosso (2017). Em doutoramento em estudos de linguagem, com concentração na área de estudos literários, pelo mesmo programa e pela mesma instituição. Graduada em Letras/Literatura pela Universidade Federal de Mato Grosso (2014). Também escreve textos de criação literária, tendo poemas e contos publicados em revistas. E-mail: rosanaarrudasouza@hotmail.com 